\title{
Teletrabalho na perspectiva da Saúde Ocupacional
}

rpso.pt/teletrabalho-na-perspectiva-da-saude-ocupacional/

Santos M, Almeida A, Lopes C, Oliveira T. Teletrabalho na perspectiva da Saúde Ocupacional. Revista Portuguesa de Saúde Ocupacional on line. 2020, volume 10, 1-35. DOI: 10.31252/RPSO.05.09.2020

\section{TELEWORK FROM THE OCCUPATIONAL HEALTH PERSPECTIVE}

\author{
TIPO DE ARTIGO: Revisão Bibliográfica
}

Autores: Santos M(1), Almeida A(2), Lopes C(3), Oliveira T(4).

\section{RESUMO}

\section{Introdução/ enquadramento/ objetivos}

A possibilidade de realizar trabalho em casa remonta há vários séculos; contudo, o desenvolvimento tecnológico permitiu a criação de novos postos de trabalho nele alicerçados e eventualmente totalmente executados fora das instalações do empregador. Para além disso, a situação de Pandemia associada ao SARSCOV-2 (vulgo COVID-19) incentivou muitas instituições a iniciar ou intensificar o Teletrabalho. Pretendeu-se com esta revisão resumir o que de mais relevante se descreveu sobre o tema, em contexto de Saúde Laboral.

\section{Metodologia}

Trata-se de uma Revisão bibliográfica, iniciada através de uma pesquisa realizada em abril de 2020, nas bases de dados "CINALH plus with full text, Medline with full text, Data base of Abstracts of Reviews of Effects, Cochrane Central Register of Controlled Trials, Cochrane Database of Systematic Reviews, Cochrane Methodology Register, Nursing and Allied Health Collection: comprehensive, MedicLatina, SCOPUS e RCAAP”.

\section{Conteúdo}

O Teletrabalho consiste em trabalhar em casa ou, pelo menos, fora das instalações convencionais do empregador, mas em local previamente estipulado e aprovado, usando tecnologia.

Nesta revisão foram resumidos dados relativos à evolução histórica do trabalho, realçando as diversas Revoluções Industriais. Foram também incluídas algumas estatísticas nacionais e sobretudo internacionais em contexto de Teletrabalho. De forma sucinta também se descrevem os principais subtipos de Teletrabalho e quais as caraterísticas desejáveis em teletrabalhores e telegerentes. Por fim, realçam-se as principais vantagens e desvantagens deste regime laboral, mencionadas na bibliografia consultada.

\section{Conclusões}

De forma generalista, a perceção das vantagens e desvantagens depende das caraterísticas do funcionário (como personalidade, flexibilidade, autonomia, competência, necessidade de socialização, postura e empenho perante o trabalho); caraterísticas do empregador (gestão, maleabilidade, valorização dos recursos humanos, meios e procedimentos); tarefas em si (facilidade ou não de serem teletrabalhadas); caraterísticas da família (número de elementos, idade dos filhos e qualidade relacional); domicílio (tamanho, iluminação, mobiliário, 
equipamentos, área reservada ou não para o Teletrabalho); transito, poluição e segurança urbana; bem como consequências para a relação com a empresa, trabalho e vida pessoal (família e sociedade); ou seja, um mesmo aspeto tanto pode ser considerado uma vantagem, como uma desvantagem, em função do contexto global. Para além disso, na realidade, o Teletrabalho tem tanta diversidade de condições e caraterísticas, que conclusões consensuais não são possíveis.

É necessário que cada instituição analise as vantagens e desvantagens de inserir o Teletrabalho e, caso decida avançar, tenha uma noção de quais são os fatores que podem potenciar e comprometer o sucesso do projeto.

PALAVRAS/ EXPRESSÕES- CHAVE: teletrabalho, saúde ocupacional e medicina do trabalho.

\section{ABSTRACT \\ Introduction/ background/ objectives}

The possibility of doing work at home dates back several centuries; however, technological development has allowed for the creation of new jobs based on it and eventually fully executed outside the employer's premises. In addition, the pandemic situation associated with SARS-COV-2 (COVID-19) has encouraged many institutions to initiate or intensify telework. The purpose of this review was to summarize the most relevant data about the topic, in the context of Occupational Health.

\section{Methodology}

This is a Review, initiated through a survey conducted in April 2020, in the databases "CINALH plus with full text, Medline with full text, Database of Abstracts of Reviews of Effects, Cochrane Central Register of Controlled Trials, Cochrane Database of Systematic Reviews, Cochrane Methodology Register, Nursing and Allied Health Collection: comprehensive, MedicLatina, SCOPUS and RCAAP”.

\section{Content}

Telework is working at home, or at least outside the employer's conventional facilities, but in a previously stipulated and approved location, using technology.

In this review, data on the historical evolution of the work were summarized, highlighting the various Industrial Revolutions. Some national and especially international statistics were also included in the context of Telework. The main sub-types of Telework are also briefly described and what are the desirable characteristics in teleworkers and telemanagers. Finally, the main advantages and disadvantages mentioned in the consulted bibliography are highlighted.

\section{Conclusions}

Generally speaking, the perception of advantages and disadvantages depends on the employee's characteristics (such as personality, flexibility, autonomy, competence, need for socialization, posture and commitment to work); characteristics of the employer (management, malleability, valorization of human resources, means and procedures); the tasks themselves (ease or not of being teleworked); family characteristics (number of elements, age of children and relational quality); the household (size, lighting, furniture, equipment, area exclusive or not for the Telework); traffic, pollution and urban safety; as well as consequences for the relationship with the company, work and personal life (family and society); that is, the same aspect can be considered both an advantage and a disadvantage, depending on the global context. Furthermore, in reality, Telework has such a diversity of conditions and characteristics, that consensus conclusions are not possible.

It is necessary for each institution to analyze the advantages and disadvantages of inserting the Telework and, if it decides to proceed, have a sense of what are the factors that can enhance and compromise the success of the project.

KEY WORDS: telework, occupational health and occupational medicine. 


\section{INTRODUÇÃO}

A possibilidade de realizar trabalho em casa remonta há vários séculos; contudo, o desenvolvimento tecnológico (telefone/ telemóvel, internet, e-mail, plataformas para reuniões com imagem e som) permitiu a criação de novos postos de trabalho nele alicerçados e eventualmente totalmente executados fora das instalações do empregador. Para além disso, a situação de Pandemia associada ao SARS-COV-2 (vulgo COVID19) incentivou muitas instituições a iniciar ou intensificar o Teletrabalho, numa escala jamais vista anteriormente. Pretendeu-se com esta revisão resumir o que de mais relevante se descreveu sobre o tema, em contexto de Saúde Laboral.

\section{METODOLOGIA}

Em função da metodologia PICo, foram considerados:

-P (population): trabalhadores com possibilidade de realizar Teletrabalho.

-I (interest): influência do teletrabalho na saúde e segurança dos trabalhadores

-C (context): saúde ocupacional nas empresas com postos/ tarefas passíveis de serem executados em teletrabalho.

Assim, a pergunta protocolar será: Quais as vantagens e desvantagens do teletrabalho para a saúde e segurança do trabalhador?

Foi realizada uma pesquisa em abril de 2020, nas bases de dados "CINALH plus with full text, Medline with full text, Database of Abstracts of Reviews of Effects, Cochrane Central Register of Controlled Trials, Cochrane Database of Systematic Reviews, Cochrane Methodology Register, Nursing and Allied Health Collection: comprehensive, MedicLatina, Academic Search Ultimate, Science Direct, Web of Science, SCOPUS e RCAAP".

No quadro 1 podem ser consultadas as expressões/ palavras-chave utilizadas nas bases de dados.

\section{CONTEÚDO}

\section{Definição}

O Teletrabalho (TT) consiste em trabalhar em casa (1-13) ou pelo menos fora das instalações convencionais do empregador (3-6, 8-11, 14-30), mas em local previamente estipulado e aprovado(25)(31)(32), usando tecnologia (2-4, 9-11, 14, 15 ,19, 21, 22, 24, 25, 27-29, 33-35) |internet (1)(8)(15)(28), email(1)(3), videoconferência(3), telefone/ telemóvel(1)(3)(8)(17)(28), redes sociais(1), computador(1)(4)(6)(15)(17)(20)(28)(36)|, havendo maior flexibilidade para gerir o horário(10)(11)(12)(16)(18) e transmitindo geralmente os resultados também através de telecomunicação(20)(23).

O TT pode ter ou não a figura clássica do empregador(4) e ser em horário total(4)(25) ou parcial (ou seja, intercalando com momentos presenciais)(6)(25) e/ ou executando tarefas enquanto se desloca. Na realidade, as diferentes definições e possibilidades dificultam as estimativas de quantos funcionários abarca(4) e outras estatísticas associadas. A relação de subordinação ao empregador não define o TT(6).

De certa forma, leva-se o trabalho ao funcionário em vez do funcionário ao trabalho, pelo menos uma vez por semana(9), segundo algumas definições.

\section{Sinónimos e termos associados}


O norte-americano Jack Nilles é considerado o pai do TT(21)(29)(37), uma vez que na primeira metade da década de setenta(21)(29), criou o termo "teleworking" (ainda que já existisse o conceito de "telecommuting"(11)(21)(28), para descrever os postos de trabalho com a possibilidade de os funcionários ficarem, às vezes, a trabalhar em casa(38), um ou mais dias por semana, substituindo total ou parcialmente os deslocamentos ao empregador(34)). Como a palavra "commuting" não tem tradução direta para a maioria das línguas europeias, teve menos aceitabilidade(21)- por isso, nos EUA usa-se mais o termo "telecommuting" e na Europa "telework"(25)."Tele" vem do idioma grego e significa longe, à distância(11). Associados a estes conceitos, surgiram os termos de "Teletrabalhador" ou "Cibertrabalhador"(13).

Por sua vez, Telemática é a aplicação da informática às telecomunicações(11). O TT conta com o apoio da tecnologia/ telemática(11)(28)(35)(37) (sem esta será apenas homeoffice)(35).

Outros termos usados na altura foram networking e remote working(28), bem como "virtual office"(21) ou "telework"(11).

\section{Evolução Histórica}

A Revolução Industrial ocorreu entre 1760 e 1840 em Inglaterra e caraterizou-se pela transição entre metodologias de produção artesanais e as mecanizadas, com utilização de recursos energéticos diferentes dos até aí mais usados (como o carvão e o desenvolvimento posterior da locomotiva). O aumento da produção teve igual reflexo no lucro, o que incentivou ainda mais a mecanização. Muitos camponeses deslocaram-se para os centros urbanos, originando uma nova classe social- proletariado. Como a produção em série fica mais barata, os artesãos deixaram de conseguir escoar os seus produtos e juntaram-se à classe operária, abandonando o trabalho no domicílio e indo exercer nas instalações do empregador. O mercado de trabalho tornou-se então mais competitivo(35).

Tal originou uma sociedade capitalista, com produção em massa e acesso de bens a uma percentagem maior da população (sendo que antes os mesmos só estavam disponíveis para uma minoria privilegiada). A substituição do trabalho humano por máquinas, degradou as condições de trabalho, criando-se postos com turnos muito prolongados, más condições laborais e baixos salários(24)(34); os locais de trabalho passaram a ser mais poluídos e a ter mais sinistros. Foram dados os primeiros passos para a divisão, repetição e especialização da tarefa, de forma a aumentar a produtividade(34).

A segunda Revolução Industrial ocorreu em meados do século XIX, apoiada pela eletricidade, petróleo, aço e diversos agentes químicos; propiciando o desenvolvimento de outros países para além da Inglaterra, como a Alemanha e os EUA. Aqui aperfeiçoou-se a especialização da tarefa e produção em série, baixando ainda mais o custo(35).

No entanto, alguns investigadores consideram que a verdadeira origem do TT ocorreu em 1857, com Edgard Thompson, na empresa ferroviária Penn Railroad, uma vez que usava o telégrafo privado para controlar equipamentos à distância(39).

Taylor e Ford iniciaram o trabalho em série e cronometrado, no século XX, permitindo a produção em larga escala, em menos tempo e a preços inferiores, baseado num número elevado de supervisores, trabalhadores especializados numa só tarefa e processos produtivos semi-automatizados; contudo, o descontentamento dos funcionários, por sua vez, foi diminuindo a produção, segundo algumas estimativas. Assim, as relações laborais precárias e o trabalho informal aumentaram em conjugação com o desemprego(13).

Outros consideram que o trabalho à distância se iniciou verdadeiramente na década de cinquenta, quando algumas partes do processo produtivo eram realizadas no domicílio dos funcionários e posteriormente terminadas na empresa(25).

A empresa IBM, na década de 70, com o objetivo de potenciar a comunicação e partilha de dados entre os funcionários, criou o conceito de eliminar as paredes dos escritórios e fomentaram a rotatividade física dos mesmos; ainda que nem todos tenham apreciado a alteração, o efeito global foi positivo. Após estes resultados, 
o investigador norte-americano Jack Nilles iniciou um projeto com uma instituição de Los Angeles, na qual se criaram escritórios domiciliares e satélite. Ele concluiu que se diminuíam os custos e a poluição ambiental, potenciando a produtividade, ainda que pudesse surgir algum isolamento social(25).

O TT surgiu oficialmente na década de 70, devido ao desenvolvimento da tecnologia(28)(29), crise energética(13)(25)(28), recessão económica americana(28), necessidade de diminuir as viagens de carro(25) e evolução do mercado de trabalho(13); ele traz flexibilização de horário, lugar e modo de trabalhar(29).

Jack Nilles(8-11) foi um físico norte-americano, que trabalhou também para a Força Aérea e na NASA(9)(11) e tentou resolver/ atenuar os problemas de trânsito(9)(11)(40); bem como a separação marcada entre zonas residenciais e de trabalho, aumento do preço dos combustíveis e poluição atmosférica(21); coexistiu na altura uma recessão económica mundial, devido à crise petrolífera, como já se mencionou, onde foi imperioso flexibilizar as empresas e reduzir as despesas, para que se tornassem mais competitivas(8)(40); ou seja, lançou a ideia de inverter a posição do local de trabalho e trabalhador(11). De certa forma, o TT faz o inverso da Revolução industrial, na qual o crescimento surgia em torno de um polo industrial e em sua função(6). Numa fase inicial tal ocorria apenas em alguns escassos dias por mês(2). A ideia de trabalhar em casa não foi inicialmente bem recebida; após Nilles trocar de empregador conseguiu investigar o tema, redigindo em 1974 um livro sobre o assunto; nos anos seguintes algumas das mais importantes empresas aderiram ao TT(11). Este foi mais divulgado/ desenvolvido a partir da década de 90, quando a evolução tecnológica o aperfeiçoou e quando se passaram a valorizar mais as preocupações relativas à poluição(2).

A energia nuclear não deu origem a outra Revolução Industrial, devido aos aspetos negativos associados, constatados na segunda Guerra Mundial. Contudo, de certa forma, esta acabou na mesma por ocorrer, após esse evento bélico, através da introdução da robótica e informática, potenciando ainda mais a produtividade e competitividade, levando ao crescimento acelerado de alguns países(35).

Por fim, após a Guerra Fria e a queda do Muro de Berlim (1989), houve internacionalização dos mercados, com acentuadas alterações políticas e legislativas, procurando-se desenvolver atividades nos países com mão-deobra mais barata, aumentando ainda mais o lucro e a competitividade, aliada à revolução digital, possibilitando o surgimento do TT(35).

Para além disso, alguns investigadores acreditam que não estamos muito longe da fase em que o trabalhador terá de concorrer com a inteligência artificial no mercado de trabalho(35).

O mercado dos serviços aumentou paralelamente à evolução tecnológica e a globalização facilita o deslocamento do trabalho para os lugares mais adequados(13). Contudo, simultaneamente, a contínua evolução da tecnologia extinguiu alguns postos de trabalho(24).

A divulgação da internet potenciou a possibilidade de executar TT, mas este ainda está numa fase inicial nos países mais atrasados tecnologicamente(41). Ainda assim, está a aumentar globalmente, ainda que tal apresente alguns desafios para o trabalhador, chefia, gestor e empregador(5).

As cidades são moduladas pelo efeito das tecnologias de informação e comunicação; o TT consegue diminuir o trânsito e descentralizar o desenvolvimento. Os centros urbanos evoluíram desde o conceito de cidade medieval murada até às cidades industriais e do automóvel e, agora, a cibercidade/ cidade virtual. A internet redefiniu as distâncias e o acesso a alguns serviços(40).

O TT é uma forma de trabalho flexível, resultando da evolução tecnológica e está a tornar-se mais prevalente, desenvolvido à distância (fora da sede do empregador), total ou parcialmente. Ou seja, é um trabalho que se desloca até o funcionário e não o inverso(11).

Com a evolução das novas formas de trabalho, torna-se necessário equilibrar a flexibilidade com o direito dos trabalhadores. Alguns países tentam também conjugar a flexibilidade com a segurança, criando o conceito de flexisegurança, na tentativa de equilibrar interesses aparentemente opostos do Estado, Funcionários e Empregadores(11).

A automatização e robotização, eliminando postos de trabalho, criou a necessidade de surgirem novas especializações, polivalências e multifunções, fomentando a origem de novos tipos e formas de trabalhar(11). 
Acredita-se que os recursos subcontratados a outras empresas serão cada vez mais frequentes, resultando na diminuição do número de colaboradores internos- "downsizing”(11).

O teletrabalho reflete a evolução do mercado de trabalho, atenuação de fronteiras e mundialização da economia. A maior competitividade exige mais produtividade e maior racionalização de custos, sem diminuir a qualidade(35).

Na generalidade dos países, o emprego deixou de ter um vínculo permanente, adquirindo maior flexibilidade física e temporal e surgiram novas formas de produção(34).

Nos EUA, quer o governo, quer as empresas privadas têm encorajado o TT(17). Contudo, mesmo dentro desta realidade nacional, algumas agências governamentais permitem o mesmo e outras não. Tal poderá justificar-se pelo facto de existirem diferentes preocupações/ metas climáticas, legislações, predomínios etários dentro da população ativa, tipos de família (casal, família monoparental) e respetivas necessidades específicas. Por exemplo, uma comunidade heterogénea e/ ou com problemas sociais preferirá o contato presencial com as agências governamentais, face à maior desconfiança do contato digital. A criação de novos postos e a aquisição de equipamento tecnológico também poderá constituir um entrave em alguns casos(32).

Enquanto que nos EUA houve uma progressão inicial e depois um abrandamento, na Europa verificou-se uma fase de resistência inicial e desenvolvimento posterior, na década de noventa(8).

Em Portugal o TT surgiu por volta de 1995(8) e foi regulado pela primeira vez em 2003, no Código do Trabalho, com os artigos 233 a $243^{\circ}$. Caso o trabalhador tenha filhos até três anos de idade, o TT seja compatível com as funções e o empregador tenha meios adequados, o funcionário tem direito a ele(21).

Ele está mais desenvolvido em empresas privadas e tecnológicas(9).Para que possa existir TT é necessário que existam sistemas de mensagens instantâneas (chat), salas de "bate-papo", telefone, videoconferência e/ ou teleconferência(23); ele é por isso incompatível com alguns setores profissionais(24).

\section{Estatísticas Internacionais e Nacionais}

Mundialmente, a maior população de teletrabalhadores reside nos EUA(34)(40). A América do Norte, Europa ocidental e Japão totalizaram cerca de 78\% dos teletrabalhadores mundiais em 2003(40).

\section{Estados Unidos da América}

Nos EUA, o TT variou de 7\% em 1997 a 9.5\% em 2010, considerando todos os setores profissionais(31). Em 2000 estimou-se que existiam cerca de 23,6 milhões de trabalhadores nessa modalidade(17); em 2004, o valor estimado foi de 24,1 milhões(2)(4) (18,3\% da população ativa(2)(4)(42)), no regime de pelo menos um dia por mês. Outro artigo mencionou que, em 2002, havia 25\% de teletrabalhadores(8); passando em 2005/6 a ser de 63(2)(4) e, em 2011, 73\%(2). Acredita-se que cerca de 10\% dos TT, apenas o fazem um dia por semana; contudo, $2 \%$ do setor privado (2,2 milhões) fazem sempre TT a partir de casa. 16,5 milhões são autoempregos e 7,6 milhões trabalham para empregadores com sedes distantes(4)(8). Outros investigadores apresentam números mais modestos, na ordem dos 10 milhões de teletrabalhadores. Na realidade é muito difícil comparar valores entre estudos devido à diversidade de subtipos e regimes de TT. Neste país, por exemplo, cerca de $20 \%$ dos teletrabalhadores executa as suas tarefas em trânsito(24).

\section{Europa}

No global de 27 países europeus o TT passou de 5\% em 2000 para 7\% em 2005(9)(31). Contudo, em 2002, um estudo estimou cerca de $13 \%(8)$.

Em 2010 cerca de 15,2\% da população ativa holandesa trabalhava com base no uso do computador, fora das instalações do empregador. Contudo, $27 \%$ da população ativa desse país não ficaria satisfeita a fazer TT e $18 \%$ não gostava de ter de gerir de forma mais ativa o seu tempo de trabalho(16). A República Checa, Dinamarca e a Bélgica têm mais teletrabalhadores (15, 14 e 13\%, respetivamente); por sua vez, em situação oposta estão a Itália, Portugal e a Bulgária (com cerca de $2 \%$ cada); de forma genérica, os países nórdicos tem prevalências 
superiores aos mediterrânicos. Em 1999, por exemplo, existiam cerca de dois milhões de funcionários neste contexto, na Alemanha(8). O TT está a crescer em países como a França, Alemanha, Itália, Holanda, Reino Unido e Suécia, sobretudo a tempo parcial (também trabalhando presencialmente)(11). O maior crescimento foi na República Checa e Dinamarca; bem como Bélgica, Holanda, Luxemburgo e Noruega(9). Na República Checa o número de indivíduos em TT aumentou cinco vezes entre 2000 e 2005. Na Bélgica, Dinamarca e Letónia esse valor duplicou. No entanto, na Bulgária, Chipre, Luxemburgo, Roménia e Portugal registou-se uma diminuição. Em França houve um aumento de 7 para 12\%, entre 2007 e 2012. A Suécia, por exemplo, passou de 36 para 51\% entre 2003 e 2014(24). Outro estudo mencionou que em 2004 30\% da população ativa da Finlândia fazia TT; 25\% na Holanda, 20\% na Dinamarca, 12\% em Inglaterra, 10\% França e 7\% em Itália(34).

Em 1999, em Portugal, existiam cerca de 100.000 funcionários (2,2\% da população ativa). Contudo, foi o primeiro país europeu a disciplinar juridicamente o TT (em 2003), como já se mencionou(8). Entre teletrabalhadores, em 2005, existiam 1,8\% de indivíduos a tempo parcial e apenas 0,4\% a tempo inteiro(9).

\section{Resto do mundo}

O Brasil é o terceiro país que mais utiliza o TT(6); em 2001(8) e 2007 foram estimados cerca de três milhões(43). Aqui, cidades mais poluídas como S. Paulo, por exemplo, têm mais motivação para incrementar o TT(24)- no centro deste estado existem cerca de 362 telecentros(11). Nesta cidade, $23 \%$ dos trabalhadores do setor privado faziam TT em 2008. O Brasil em 2008 contava já com 10.600.00o funcionários em TT(40)(43), sobretudo a nível de instituições privadas; ou seja, quase um quarto da população ativa faz TT pelo menos uma vez por mês e $8 \%$ faz quase diariamente (em algumas microempresas pode chegar a 15\%)(40).

Em 2004 estimou-se que 10\% da população ativa no Canadá fazia TT(34).

Na Coreia do Sul o número de funcionários do governo em TT variou de 17 para 20\%, entre 2013 e 2015, ainda que no último ano $44 \%$ tivesse oportunidade para a ele aderir(18).

Em 1999, existiam cerca de dois milhões de teletrabalhadores no Japão(8). Cerca de 16\% destes fazem TT móvel (em trânsito)(24). Em 2004 16\% da população ativa fazia TT(34).

A India, por sua vez, apresenta um crescimento lento do TT(24).

\section{Outros detalhes}

Um estudo comparou funcionários em TT e em trabalho presencial, mas todos com uma primeira fase de TT e concluiu que os primeiros eram 13\% mais produtivos (assinalando como justificação o menor número de interrupções); estes tinham também cerca de metade dos conflitos domésticos, estando por isso mais satisfeitos. Contudo, foram menos promovidos (cerca de 50\%). Neste caso, após experimentar, $77 \%$ dos funcionários preferiu manter o TT(6).

A OIT (Organização Internacional para o Trabalho) defende que o TT aumenta a produtividade em 45\% (devido à melhor qualidade de vida e autonomia), bem como pelo maior número de horas de trabalho (ainda que existam empregadores que colocam objetivos para TT 10 a 20\% mais elevados que para os funcionários presenciais)(6).

No global, a maioria dos teletrabalhadores é do sexo masculino (59\%); contudo, considerando a versão a tempo inteiro, a situação inverte-se (70\% são do sexo feminino) e está entre os 26 e os 45 anos. 47\% são casados e $23 \%$ são casados e com filhos. 61\% detém diploma universitário(13).

Alguns investigadores acreditam que o TT poderia ser executado em cerca de um quinto dos empregadores, mundialmente(44). Por sua vez, Bill Gates afirmou que, até 2050, metade da população ativa terá TT(43).

\section{Subtipos}

O TT pode ser a tempo inteiro, parcial(6)(8)(11) ou ocasional(11); presentemente, a tempo parcial é mais frequente(21). Pode também existir um regime misto(25) (ou seja, trabalho presencial misturado com TT, por exemplo, à noite)(20), mas não só. 
Ele pode ocorrer em:

-casa do trabalhador(6)(8-12)(20)(21)(24)(25)(28-30)(33)(35)(37)(39)

-ser móvel ou nómada (às vezes em diversas cidades, em locais com acesso a internet de qualidade e alguma privacidade, como aeroportos, livrarias, bibliotecas, cibercafés), ou seja, um escritório virtual(6)(8)(10)(11)(21) $(28)(30)(33)(37)$

-escritórios satélite do empregador (mais próximos da residência do trabalhador que a sede(6)(8-11)(21)(24) (28)(30)(33)(37)

-telecentros(ou cowork), ou seja, áreas que integram profissionais de diferentes empresas ou por conta própria e assim os funcionários mantêm alguma sociabilização, partilha de ideias, sendo possível em alguns casos receber um cliente uma área com mais privacidade(6)(8-11)(20)(21)(24)(25)(28)(29)(33)(35)(37)(39); os telecentros não diminuem o número de viagens mais sim as distâncias e tempo dispendido(40).

-"telecottage" (telecentro comunitário situado nas zonas mais rurais, instalado geralmente por iniciativa da administração pública ou comunidade; teve início na Suécia)(11)(35)(37)

-escritórios turísticos (localizados em locais destinados ao turismo, de forma ao trabalhador e sua família desfrutarem de tal)(35)

-hoteling (telecentro instalado num quarto de hotel e/ou sala de reuniões)(35)

-remoto,offshore (escala global)/ transfronteiriço ou transnacional(8)(9)(11)(28)(33)(35).

Quanto ao tipo e forma de comunicação o TT pode ser:

-offline (sem comunicação constante entre funcionário e empregador; envia depois)

-onewayline (comunicação unidirecional)

-online (bidirecional e com controlo/ fiscalização imediatos)(11) (21) (24).

Funcionários menos habilitados e com tarefas mais rotineiras geralmente executam a versão online; os mais qualificados e criativos geralmente tem uma ligação que pode ficar offline(8).

A própria forma de designar os trabalhadores foi mudando ao logo do tempo: mão de obra no início, depois funcionários e agora colaboradores, no sentido de indicar uma progressiva autonomia e participação(22). Em relação à subordinação jurídica, o TT pode então ser:

-com subordinação(21)

-autónomo ou sem subordinação jurídica mas dependência económica(21)

-parasubordinação (situação intermédia)(24).

\section{Caraterísticas desejáveis nos Teletrabalhadores}

Se nem todas as funções podem ser teletrabalhadas, nem todos os funcionários podem ser teletrabalhadores. Para recrutar para TT, podem ser utilizados funcionários presenciais (que já conhecem a cultura da organização) ou candidatos externos; uma seleção adequada potenciará o sucesso(6)(22).

Existem algumas caraterísticas entre os trabalhadores que os podem tornar mais adequados ao regime de TT, nomeadamente:

-estarem inseridos num casal(6)(22)(38)(43)(44) ou famílias monoparentais (38), com filhos pequenos(6)(22) (38)(43)(44); ainda que, simultaneamente, também se tenha verificado que quanto maiores forem as

exigências familiares, menor capacidade terá o funcionário para trabalhar em casa- justamente por tal, alguns 
empregadores podem preferir que fique em TT os que têm menos responsabilidade familiares (45);ainda que outros autores acreditem que este proporciona mais tempo para a família(22)

-vítimas de violência doméstica (subentende-se se apenas o TT se desenrolar noutro domicílio, evitando ser encontrada no posto de trabalho pelo agressor)

-funcionários menos jovens

-indivíduos com algumas deficiências/ limitações(21)

-trabalhadores do sexo feminino, dado culturalmente ser mais usual assumirem as tarefas domésticas e familiares(18)

-ambiente doméstico estruturado(9)

-residentes em grandes aglomerados populacionais, com transito complicado (muito tempo despendido em viagens) e/ ou áreas poluídas(38) ou com viagens longas até a sede do empregador ${ }^{(6)}$

-trabalhadores com empregadores de maior dimensão(30).

-funcionários com capacidade de gerir várias dimensões em simultâneo e que respondem melhor e com mais facilidade às exigências(22)(45); ou seja, façam uma melhor gestão das prioridades e do tempo livre(22) ou do tempo no geral(9)(23)

-trabalhadores de colarinho branco, com exigência de conhecimentos/ técnicas específicas(4) e formação académica mais extensa(4)(8)(11)(24)

-funcionários que necessitam de controlar as distrações que existam no seu posto de trabalho

-indivíduos que precisam de criar um ambiente personalizado para trabalhar melhor e/ ou com mais privacidade(16)

-funcionários que não receiem aceitar medidas laborais "amigas da família", dados os eventuais conflitos com os colegas; geralmente os que têm filhos apoiam tal e os que não têm podem não concordar(18)

-maior competência em geral(13)(22)

-desempenho elevado(8)

-disciplina

-dedicação(22)

-organização(8)(22)

-maior propensão para corresponder aos objetivos

-maior disponibilidade para trabalhar

-maior capacidade de corresponder à confiança que neles foi depositada(22)

-grande capacidade para resolver problemas

-conhecer bem a instituição(8)

-autonomia, ou seja, não necessitar de supervisão(8)(9)(11)(23)

-trabalhar bem isoladamente e por longos períodos de tempo

-conciliar diversas tarefas

-equilibrar o trabalho com a vida doméstica(8) 
-ser flexível e adaptável, recetivo à mudança(8)(10)(23)

-encarar o TT como uma promoção/ privilégio (em vez de despromoção e afastamento)

-ter integridade(9)

-responsabilidade(9)(10)

-tenacidade(9)

-automotivação(9)(10)(13)

-foco

-eficiência(9)

-autodisciplina(9)(23)

-adaptabilidade à evolução tecnológica(9)

-boa capacidade de comunicação

-eficácia

-independência

-autoconfiança

-bom senso

-espontaneidade(23)

-confiabilidade

-confiança

-ter iniciativa e

-dominar a atividade(10).

No entanto, não deverão existir situações de depressão ou dependências (como comida, álcool, outras drogas) (9).

Por sua vez, as caraterísticas desejáveis num telegerente são:

-um estilo de liderança flexível e adaptável

-boa capacidade de comunicação

-competências formativas

-capacidade de antecipar problemas e fornecer soluções

-definir com clareza as tarefas e o processo de avaliação dos funcionários, incluindo divulgação dos resultados e sistemas de bonificação

-valorizar os progressos tecnológicos e as inovações que possam ser úteis

-analisar o desempenho das outras equipas e introduzir variáveis que noutras condições estejam a obter sucesso

-gerir com cuidado os dados sujeitos a sigilo e inseridos nos meios tecnológicos utilizados(6). 


\section{Teletrabalho e Trabalhadores com Deficiências}

O TT possibilita a inserção de indivíduos com deficiências no mercado de trabalho(46). Alguns TTs foram eventualmente assinalados como adequados aos indivíduos com limitações, ainda que a investigação inicial tenha dado ênfase aos empregadores(2). Apesar deste ter aumentado na sociedade em geral, tal não se verificou entre os indivíduos com limitações(14); ou seja, a percentagem destes em TT é inferior à da população geral(4); contudo, na realidade, não existem estudos robustos de prevalência global de TT nesta fração da população(2).

Para além disso, o TT não deve ser considerado adequado para todos os indivíduos com limitações; aliás alguns investigadores consideram que tal não será uma boa opção para a maioria dos indivíduos com alguma deficiência(2). No entanto, a generalidade dos autores considera ser promissor o uso do TT neste contexto. Os aspetos mais positivos são a eliminação das barreiras físicas(4) e as viagens(3)(4)(24), bem como a maior flexibilidade de horário permitindo melhor gestão da fadiga(3)(4) e da dor e eventualmente atenuar a discriminação que possa existir(4). Contudo, simultaneamente, o indivíduo pode sentir-se isolado e ter dificuldades em separar o trabalho da família(3).

Num estudo que englobou quase 1200 empregadores nos EUA, estimou-se que $80 \%$ tinha pelo menos um funcionário com limitações e $23 \%$ apresentava a possibilidade de TT; contudo, apenas $8 \%$ tinha nesta versão funcionários com limitações. Os números governamentais estimados foram de $5 \%$ de funcionários com limitações e apenas $1 \%$ destes em TT(4).

\section{Vantagens}

O agregado familiar mais prevalente alterou-se nas últimas décadas, sendo agora mais frequente os dois cônjuges trabalharem ou até existirem famílias monoparentais, o que altera a disponibilidade para prestar cuidados à família. O conflito que possa surgir geralmente afeta o bem-estar e produtividade do funcionário, o que acaba por influenciar negativamente o empregador (para além do absentismo e turnover). Logo, algumas instituições desenvolveram programas "amigos da família", sendo alguns destes baseados na flexibilidade de horário(19). Ou seja, sentindo que o empregador se preocupa, o funcionário será mais dedicado(19)(31). Se o empregador trata o funcionário com especial cuidado e atenção, deste receberá uma maior lealdade e empenho; diminui-se o turnover de funcionários e potencia-se a satisfação(31). Segundo alguns investigadores os benefícios superam as desvantagens, sobretudo para os funcionários menos jovens e/ ou com filhos(43). Os teletrabalhadores apresentam um nível mais elevado de qualidade de vida no trabalho e satisfação profissional; funcionários mais satisfeitos produzem mais(39).

A generalidade dos pais que trabalha tem dificuldade em dar apoio aos filhos, fora do horário escolar; quando a família é monoparental, tal pode intensificar-se ainda mais. Ter flexibilidade no trabalho poderá ajudar e esta pode recair na variabilidade de horário ou do local de trabalho. Nos postos pior remunerados a flexibilidade é mais diminuta ou até ausente(6). A maior flexibilidade favorece assim alguns funcionários, de modo que estes conseguem melhor coordenar as suas responsabilidades familiares e passar mais tempo com o agregado familiar- daí que, simultaneamente, possa aliviar conflitos familiares. Os trabalhadores ficam mais satisfeitos e produtivos se tal se evitar; logo deveria ser do interesse do empregador atingir tal patamar(36). Um desequilíbrio entre a vida profissional e familiar pode gerar ansiedade em qualquer funcionário. Locais de trabalho amigos das famílias diminuem a probabilidade de também existirem sintomas depressivos(47). A flexibilidade de horário permite uma melhor gestão das compras no supermercado e tarefas familiares, bem como ter miniférias/ fins de semana alargados(1).

O TT pode dar uma boa imagem da empresa; ou seja, como sendo moderna, preocupada com o ambiente e com os funcionários(6).

Na década de 90 e seguintes, considerava-se que o teletrabalho facilitava a conjugação das vidas profissional e familiar, aumentando a satisfação do trabalhador, desde que esta modalidade de trabalho não fosse imposta; ainda que os funcionários reportassem sentir falta de alguma sociabilização, simultaneamente também se sentiam mais livres e produtivos(2). 
A possibilidade de jovens mães trabalharem a partir de casa diminui a ansiedade, promove uma melhor saúde mental geral e facilita o regresso ao trabalho presencial. Um emprego amigo da família incluirá, além da flexibilidade de horário e do local de trabalho, licença de maternidade e de doença, bem como acesso a seguros de saúde e maior controlo sobre a gestão do trabalho(47), direitos esses que não existem para todos os trabalhadores, em todos os países, de forma uniforme.

Trabalhar em casa fora do horário laboral poderá ser encarado para alguns como algo positivo, dado sentirem que têm mais liberdade para decidir quando trabalhar, gerindo com mais facilidade todas as suas responsabilidades(36). Para além disso, parece que empregos que exijam muitas horas de trabalho, podem ser melhor executados em regime de TT, dado o funcionário ter mais autonomia e controlo para gerir as tarefas; ou seja, trabalham mais horas, na intensidade que preferem, sem as distrações que possam existir no local de trabalho presencial(45). O teletrabalho possibilita assim que se trabalhe ao próprio ritmo. A ausência de chefia presencial, aumenta geralmente a autonomia(6). No TT enfatiza-se mais o resultado; exercendo em função do seu biorritmo e preferências, o funcionário coloca pausas quando achar que o cansaço assim o justifica, quebrando também a monotonia e a repetibilidade(11).

O TT diminui o custo para o empregador relacionado com os imóveis, equipamento e manutenção das instalações(6).

O trabalhador deixa de estar dependente do transito, veículo próprio ou transportes públicos, bem como de condições climatéricas (chuva, inundações ou outras questões equivalentes)(6).

Indivíduos que não conseguiram manter um trabalho presencial (como mães com vários filhos, grávidas ou funcionários perto da reforma), podem conseguir geralmente fazer TT(6).

Possibilitar o TT é demonstrar que se confia no funcionário. A autoestima deste pode ser proporcional à confiança nele depositada, aumentando a perceção de compromisso com o empregador(6).

A análise global considera que o TT é uma mais valia para o funcionário (sobretudo a nível de qualidade de vida, diminuição dos custos do deslocamento e aumento da oferta de trabalho), instituição (melhor imagem) e sociedade (menos transito e poluição)(23).

A evolução tecnológica permitiu o desenvolvimento do TT que, por sua vez, inova e aumenta a competitividade das empresas; por isso, cada vez mais instituições o adotam porque têm em mente que funcionários mais satisfeitos ficam mais produtivos, criativos e inovadores(25).

Consoante a metodologia usada, o empregador pode ter dificuldade em perceber com clareza quais as horas efetivamente trabalhadas. Contudo, este controlo rígido no TT é excecional, privilegiando-se a maior liberdade de gestão da parte do funcionário(11).

O Estagiário em TT poderá ser útil, na medida em que o empregador poderá usufruir de funcionários muito jovens (às vezes até universitários), com conhecimentos teóricos e, se inseridos na empresa nesta fase, mais facilmente assimilarão a cultura organizacional. Para além disso, a sua remuneração é inferior e, como querem mostrar o seu valor, por norma dedicam-se bastante(44).

Estima-se que fazer TT em metade do horário laboral permitiria diminuir as importações de petróleo em $45 \%$, em alguns países, o que atenuaria o aquecimento global e a produtividade dos EUA aumentaria cerca de um terço. A diminuição no transito neste país associada ao TT pouparia cerca 78 milhões de dólares por ano e, se cerca de 50 milhões de americanos fizessem TT, estima-se que se evitariam cerca de 95 mil acidentes de trânsito e 1500 mortes, bem como 11 biliões de dólares em custos associados(44).

No quadro 2 estão sistematizadas algumas das vantagens do TT.

\section{Desvantagens}


No global das desvantagens, alguns investigadores consideram que estas podem ser mais penalizadoras para os funcionários versus empregador, sobretudo quando o TT é praticado a tempo integral(6). Outros autores defendem, por sua vez, que as desvantagens poderão ser menos valorizadas, de forma proporcional ao número de filhos(47).

Alguns trabalhos concluíram que o uso de dispositivos tecnológicos em casa, para além das horas normais de trabalho, pode gerar conflitos familiares, sobretudo nas situações onde não existiam limites traçados entre trabalho e não trabalho, o que aumenta as interrupções e descontinuidades, quer nas tarefas laborais, quer domésticas. Alguns elementos do agregado familiar podem considerar que o trabalho em casa deve ser feito no horário habitual e não em horas "extraordinárias". Os trabalhadores do sexo masculino parecem demonstrarse mais perturbados com as interrupções nas tarefas laborais(36). Aliás, alguns dos funcionários que passam parte do seu horário de trabalho em casa, sentem-se mais sobrecarregados com as tarefas domésticas(45).

Existe também bibliografia que descreve a possibilidade de a liberdade de horário, sobretudo se conjugada com tarefas excessivas, poder potenciar a ansiedade, coexistindo alterações no padrão de sono e/ ou de ingestão de alimentos(47).

Por vezes alguns trabalhadores colocam adereços/ símbolos (como brincos, maquilhagem ou gravata), para os familiares perceberem que estão a trabalhar(43)(44); pois uma parte significativa dos funcionários não tem uma divisão da casa exclusiva para o TT, pelo que partilha, às vezes, a área com o cônjuge, filhos e/ ou animais domésticos(43).

Também estão descritos problemas como maior dificuldade das chefias para monitorizar o desempenho e controlar eventuais atitudes negativas; daí que em algumas empresas são as chefias que decidem, em primeira mão, quem fica em TT(38).

O supervisor deverá manter-se em contato, de forma a proporcionar alguma sociabilização e atenuar o isolamento(3). A procura de ajuda a nível laboral poderá ser necessária para terminar uma tarefa; presencialmente, geralmente pede-se conselho a um colega ou chefia- tal pode ficar dificultado no TT(48). Dentro de algumas empresas, parte dos trabalhadores selecionados para fazer TT não o aceitam; pensa-se que isso poderá estar associado a determinados tipos de gestão/ chefia(18).O telegerente geralmente também é teletrabalhador. Telegestão será assim a supervisão dos teletrabalhadores, exercida virtualmente(6). Um funcionário que seja uma boa chefia presencial não implica que consiga ter o mesmo desempenho em TT e vice-versa, uma vez que a cultura de trabalho e forma de relacionar/ comunicar é diferente(6)(22).

Algumas instituições organizam visitas aos teletrabalhadores, no seu domicílio, mas verificou-se que tal causava transtorno e a deteção de presença não implica produtividade (presenteísmo). Em TT valoriza-se mais o resultado e não os processos ou timings para a ele chegar, como já se referiu. A própria tecnologia pode servir para monitorizar o TT e ser até mais exaustiva que o controlo presencial(6). Outros defendem que as visitas ao domicílio do trabalhador devem ser limitadas(8) e autorizadas previamente pelo teletrabalhador(11). O empregador tem direito a vigiar, mas sem violar os direitos do funcionário, nomeadamente a privacidade(35).

O TT não deverá ser utilizado para se obter horas extra não remuneradas ou para ter os funcionários disponíveis 24 horas por dia. Contudo, algumas instituições recusam-se a pagar horas extra aos teletrabalhadores(6)(12), o que pode intensificar o ritmo de trabalho. Aliás, algumas empresas oferecem um salário inferior para o TT porque consideram que o acesso a tal já é, em si, uma regalia(6).

Alguns empregadores desenvolveram projetos de TT e depois recuaram, dada a baixa produtividade verificada; a seleção, formação e adaptação devem ser adequadas(6).

Em alguns países o Governo promove menos o TT que as empresas privadas; acredita-se que na primeira situação poder-se-á encontrar mais resistência, sobretudo das chefias, devido à alteração que teria de existir em relação ao estilo de gestão e liderança; para além disso, neste contexto, também podem existir mais desafios técnicos e piores relações entre as chefias e os funcionários(31). Alguns estudos referem que o TT não parece alternar o turnover em instituições governamentais dos EUA, ao contrário da flexibilidade em si(19). 
Com o aumento do número de indivíduos a fazer TT, tornam-se mais relevantes as questões associadas à segurança do novo local de trabalho(17). Por vezes as condições de TT poderão não ser as ideais a nível de conforto térmico, espaço e/ ou iluminância. Deslocar o trabalho para o domicílio implica que o empregador deixará de ter controlo/ responsabilidade pelas condições de segurança; existindo normas escritas pode-se regularizar a situação e atenuar o risco, bem como realizando formação sobre o tema(15). Outros também destacam que o mobiliário poderá também não ser o mais adequado, tal como ventilação e limpeza. Se o funcionário assinar um termo de responsabilidade por estas condições, o empregador não terá que orientar tal diretamente; por outro lado, a instituição também não detém autonomia para alterar a infraestrutura do domicílio do trabalhador(6). Alguns empregadores custeiam impressora, telemóvel e outras despesas equivalentes, bem como uma quantia única para benfeitorias ergonómicas do local de trabalho domiciliar(43).

Um estudo quantificou que cerca de 60\% dos teletrabalhadores sentia que tinha sido abandonado neste contexto, sem apoio ergonómico ou técnico. Para além disso, 55\% dos teletrabalhadores avaliados referiam algias associadas aos membros superiores, dorso e pescoço, que associavam ao computador/ postura sentada mantida e mobiliário desadequado. Tal torna-se mais relevante em TT porque aqui geralmente se trabalham mais horas para corresponder às metas traçadas e/ ou tentar superar as mesmas, pela maior necessidade de provar a validade do seu trabalho(17).

Alguns investigadores também concluíram que o TT que exceda os dois dias e meio semanais, prejudica as relações com os colegas de trabalho(17), ainda que alguns considerem que os conflitos de trabalho(18)- família possam diminuir com o aumento do número de horas em TT(17). Ou seja, os funcionários presenciais podem invejar os que estão em TT(22).

A ligação afetiva/ emocional dos funcionários ao empregador/ projeto geralmente é proporcional ao contato que têm e à visibilidade que ocupam, aspetos estes geralmente prejudicados no TT(5).

O trabalhador tem direito a descansar e se desconectar totalmente do trabalho; neste âmbito alguns autores descrevem de forma um tanto dramática o conceito de "escravidão tecnológica"(7)(13); ou seja, salientam a falta de acesso a períodos rígidos de descanso (férias, feriados, fins de semana)(24)(35). Alguns autores descrevem que os teletrabalhadores podem, por isso, se sentir explorados, inseguros e/ ou ansiosos(22); ou seja, consideram que o TT compromete os direitos conquistados pelos funcionários, incluindo o acesso a atividades sindicais(13).Para o trabalhador conseguir usufruir do lazer é necessário que consiga desconectar-se do trabalho(49).

Só há autonomia plena quando não há subordinação; assim, neste contexto, os teletrabalhadores podem ter ainda menos autonomia, uma vez que a fiscalização de desempenho pode ser ainda mais intrusiva e durante todo o horário de trabalho(7)(24)(11)(44) (quando ligou e desligou o computador, quanto tempo usou em cada tarefa, quanto tempo o aparelho esteve ligado sem ninguém lhe mexer), ainda que se possa trabalhar com uma maior flexibilidade de horário. As instruções, ordens e cobranças podem ser enviadas a qualquer momento(7). Ainda que o teletrabalhador tenha autonomia para gerir o seu tempo, não costuma controlar o tempo de trabalho, uma vez que é avaliado pelo que produz (resultados), como já se mencionou, e não pelas horas que permanece a trabalhar(29). O conceito de autonomia em TT é assim complexo, uma vez que existem prazos e outras condições que se podem tornar limitantes; no entanto, ainda assim, ela costuma ser superior em tarefas mais diferenciadas(20). O facto dos meios tecnológicos serem vigiados pelas chefias pode perturbar ainda mais a comunicação(5). O empregador é responsável por garantir a proteção de dados e, se adotar algum sistema de vigilância do funcionário, este deve respeitar a sua vida pessoal; o empregador tem direito a saber se o funcionário está a trabalhar e em que moldes, mas os aspetos fiscalizados deverão ser explicitados previamente(11).

Outra desvantagem poderá ser o facto dos teletrabalhadores precisarem de ter uma boa capacidade de autogestão e controlo do tempo, uma vez que não têm um superior hierárquico presente para fiscalizar/ orientar $\operatorname{tal}(7)$.

O isolamento, um dos aspetos negativos mais salientados, pode ser atenuado através de reuniões com a equipa ou só com as chefias, presenciais e/ ou online(8) (pelo menos trimestralmente), em locais como hotéis, cafetarias ou restaurantes(43); outros sugerem ainda almoços de trabalhos com toda a equipa e/ ou encontros em bares, fora do horário de trabalhos ("happyhours"), ao encargo do empregador(22); bem como viagens 
para reunir a equipa (e aí custear voos, táxis, refeições)(44). Para que não haja discriminação, informações importantes devem ser colocadas em circulares e enviadas para todos os funcionários. Está também descrito que o eventual isolamento e dificuldade na progressão da carreira poderão ser atenuados com fases de trabalho presencial, intercaladas(23).Um dos principais desafios é sentir-se integrado na empresa(43). Alguns defendem que o isolamento social pode aumentar com o tempo, sobretudo quando o TT é executado em horário integral(29).

O TT pode comprometer a aprendizagem e a inovação(30), segundo alguns investigadores; outros discordam e defendem que a formação pode ser online(6).

A sociedade da informação ou telemática precisa de trabalhadores qualificados, sendo que tal pode contribuir para a marginalização de funcionários que não tenham esses conhecimentos (infoexclusão ou exclusão tecnológica)(13).

No quadro 3 estão sistematizadas algumas das desvantagens do TT.

\section{Aspetos ambivalentes que podem, simultaneamente, ser considerados vantagem ou desvantagem, consoante a personalidade ou perspetiva}

Alguns funcionários podem encarar as interrupções nas tarefas laborais como algo positivo, como por exemplo, uma pausa dedicada a atividades parentais(36).

Segundo alguns autores, não há consenso que o TT melhore ou piore a vida familiar, devido ao eventual conflito pela falta de limites entre as tarefas laborais e familiares, perturbando ambas; por exemplo, num estudo com mais de 16.000 participantes percebeu-se que gerava menos conflito ter horário convencional para trabalhar, versus horário flexível ou TT. Contudo, por sua vez, alguns investigadores também salientam que trabalhadores com uma vida familiar mais ou menos conflituosa podem escolher fazer TT ou ter horário flexível, o que poderá enviesar as conclusões. Para além disso, alguns horários são auto reportados, pelo que podem não corresponder à realidade. Também é possível que, considerando variáveis como apoio do cônjuge e cultura organizacional, tal altere a intensidade do conflito trabalho e família percecionado(1).O sucesso do TT depende também da postura da chefia a nível de apoio, comunicação e confiança(5).

O TT exige autodisciplina, organização, iniciativa e prazer em trabalhar sozinho; logo, não será adequado para qualquer funcionário; este deverá ser flexível e criativo, com baixa dependência do contato social, responsável, adaptável, confiável, competente, focado, com boas capacidades de comunicação, não necessitar de supervisão e ser seguro(6).

Os teletrabalhadores, mesmo doentes, por vezes, mantêm o seu trabalho, embora que eventualmente possam estar um pouco menos produtivos; contudo, se estivessem em trabalho presencial, provavelmente faltariam(6) e a possibilidade de se manter sempre a trabalhar é obviamente uma vantagem ou desvantagem, consoante a postura do trabalhador.

Como o aumento da distância entre funcionário e a chefia, o controlo por vezes ocorre mais através da afixação de metas(7), o que poderá agradar ou desagradar ao funcionário.

\section{DISCUSSÃO/ CONCLUSÃo}

Como principais limitações da generalidade dos artigos existentes podem citar-se que nem todos os estudos abarcaram empregadores de dimensão elevada e/ ou amostras razoáveis, ou levaram em conta a idade, sexo, anos a exercer naquele empregador/ posto e caraterísticas da gestão/ chefia ou qualidade do ambiente familiar.

De forma generalista, a perceção das vantagens e desvantagens depende das caraterísticas do funcionário (como personalidade, flexibilidade, autonomia, competência, necessidade de socialização, postura e empenho perante o trabalho); caraterísticas do empregador (como gestão, maleabilidade, valorização dos recursos humanos, meios e procedimentos); caraterísticas das tarefas em si (facilidade ou não de serem 
teletrabalhadas); caraterísticas da família (número de elementos e idade dos filhos e qualidade relacional); caraterísticas do domicílio (tamanho, iluminação, mobiliário, equipamentos, área reservada ou não para o TT); transito, poluição e segurança urbana; bem como consequências para a relação com a empresa, trabalho e vida pessoal (família e sociedade); ou seja, um mesmo aspeto tanto pode ser considerado uma vantagem, como uma desvantagem, em função do contexto global. Para além disso, na realidade, o TT tem tanta diversidade de condições e caraterísticas, que conclusões consensuais não são possíveis.

É necessário que cada instituição analise as vantagens e desvantagens de inserir o TT e, caso decida avançar, tenha uma noção de quais são os fatores que podem potenciar e comprometer o sucesso.

\section{CONFLITOS DE INTERESSE, QUESTÕES ÉTICAS E/ OU LEGAIS}

Nada a declarar.

\section{AGRADECIMENTOS}

Nada a declarar.

\section{BIBLIOGRAFIA}

1. Higgings C, Duxbury L, Julien M. The relationship between work arrangements and work-family conflict. Work. 2014, 48, 69-81. DOI: 10.3233/WOR-141859

2. Moon N, Linden M, Bricout J, Baker P. Telework rationale and implementation for people with disabilities: considerations for employer policymaking. Work. 2014, 48, 105- 115. DOI:10.3233/WOR131819

3. McNaughton D, Rackensperger T, Dorn D, Wilson N. "Home is at work and work is at home": telework and individuals who use augmentative and alternative communication. Work. 2014, 48, 117- 126. DOI: 10.3233/WOR-141860

4. Linden M, Milchus K. Teleworkers with disabilities; characteristics and accommodation use. Work. 2014, 47, 473-483. DOI: $10.3233 / \mathrm{W}=\mathrm{R}-141834$

5. Dahlstrom T. Telecommuting and Leadership Style. PublicPersonnel Management, 2013, 42(3), 438-451. DOI: 10.1177/0091026013495731

6. Silva V. A gestão do Teletrabalho. Mestrado em Administração. Universidade Metodista de S. Paulo, Faculdade de Administração e Economia. 2014, 1-112.

7. Melo C. O Teletrabalho e o direito à desconexão. Revista da Esman. 2016, 10(10), 231-249

8. Guerra A. O regime especial de Teletrabalho- as implicações nas relações laborais. Mestrado em Direito do Trabalho- Faculdade de Direito da Universidade Católica Portuguesa. 2013, 1-140.

9. Santos P. Teletrabalho nos Tribunais Judiciais, Administrativos e Fiscais em Portugal- Realidade ou Ficção? Mestrado de Administração Pública. Instituto Universitário de Lisboa. 2018, 1-115.

10. Oliveira M. Teletrabalho e atitudes frente à mudança. Mestrado em Saúde Pública, Faculdade de Planaltina, Universidade de Brasília. 2019, 1-122.

11. Rodrigues A. Teletrabalho: a tecnologia transformando as relações de trabalho. Mestrado em Direito do Trabalho e da Seguridade Social. Faculdade de Direito, Universidade de S. Paulo. 2011, 1-142.

12. Taschetto M, Frochlich C. Teletrabalho sob a perspetiva do profissional de Recursos Humanos do Vale dos Sinos e Paranhana no Rio Grande do Sul. Recape. 2019, 9(3), 349- 375. DOI:10.20503/recape.v9i339652

13. Busnello R, Palma E. Teletrabalho: o equívoco da sedução: a realidade por detrás do véu. Revista de Direito Viçosa. 2018, 10(1), 159-192.

14. Linden M. Telework research and practice: impacts on people with disabilities. Work. 2014, 48, 65-67. DOI: $10.3233 /$ WOR-141857.

15. Ramírez S, Rúa N. El concepto de teletrabajo: aspectos para la seguridade y salude nelempleo. CES Salud Publica. 2014, 5, 82- 91. 
16. Vink P, Blok M, Formanoy M, Korte E, Groenesteijn L. The effect of new ways of work in the Netherlands: national data and a case study. Work. 2012, 41, 2600- 2604. DOI: 10.3233/WOR-2012-1027-2600

17. Robertson M, Schleifer L, Huang Y. Examining the macroergonomics and safety factors among teleworkers: development of a conceptual model. Work. 2012, 41, 2611-2615. DOI: 10.3233/WOR-20121029-2611

18. Bae K, Lee D, Sohn H. How to increase participation in telework programs in US Federal Agencies: examining the effects of being a female supervisor, supportive leadership and diversity management. PublicPersonnel Management. 2019, 48(4), 565-583. DOI: 10.1177/009102019832920

19. Caillier J. Does satisfaction with family- friendly programs reduces turnover? A panel study conducted in USA Federal Agencies. Public Personnel Management. 2016, 45(3), 284-307. DOI: 10.1177/0091026016652424

20. Rosenfield C, Alves D. Autonomia e Trabalho Informacional: o Teletrabalho. Dados. 2011. 2011, 54(11), 207-233

21. Almeida M. O Teletrabalho e o direito a teletrabalhar. Universidade Católica Portuguesa- Faculdade de Direito- Escola do Porto. 2019, 1-53.

22. Aderaldo I, Aderaldo C, Lima A. Aspectos críticos do Teletrabalho em uma companhia multinacional. Cadernos EBAPE. Br. 2017, 15, artigo 8, 511-533. DOI: 10.1590/1679-354160287

23. Giglio C, Galegale N, Azevedo M. Vantagens do Teletrabalho: análise da produção científica nos principais congressos brasileiros. GEPROS. Gestão de Produção. Operações e Sistemas. 2018, 14(4), 128143. DOI: $10.15675 / g e p r o s . v 13 i 4.1975$

24. Melo M. Teletrabalho: um estudo comparado entre Portugal e Brasil sobre a transformação das relações de trabalho. Mestrado em Direito, Faculdade de Direito da Universidade do Porto. 2018, 1- 60.

25. Neves C. Relação entre Teletrabalho e Satisfação dos Colaboradores: um estudo de caso com engenheiros de software. Mestrado em Economia e Gestão da Inovação. Faculdade de Economia da Universidade do Porto. 2019, 1-43.

26. Christenson K, Schneider B, Butler D. Families with school age children. The future ofchildren. 2011, 21(2), 69-100.

27. Nascimento C. A necessidade de regulamentação do Teletrabalho como meio de efetivação dos direitos fundamentais dos trabalhadores. Mestrado em Fundamentos Constitucionais do Direito Público e Privado. Faculdade de Direito, Pontifícia Universidade Católica do Rio Grande do Sul. 2012, 1-20

28. Bald A. Direito à desconexão frente aos direitos e deveres do empregado no contrato de trabalho especificamente Teletrabalho. Mestrado em Direito e Processo do Trabalho. Centro Universitário Univates. 2016, 1-21.

29. Leite A, Lemos D, Schneider W. Teletrabalho: uma revisão integrativa da literatura internacional. Revista Contemporânea de Economia e Gestão. 2019, 17(3), 187- 210.

30. Arias B. Gestão do Conhecimento, Aprendizagem Organizacional e Inovação em empresas Colombianas que adotaram o Teletrabalho. Doutoramento em Ciências da Informação. Universidade Federal de Minas Gerais. 2019, 1-196.

31. Choi S. Managing flexible work arrangements in Government: testing the effects of Institutional and Managerial Support. Personnel Management. 2018, 47(1), 26-50. DOI: 10.1177/oo910260

32. Kmon M, Jeon S. Why permit telework? Exploring the determinants of California City Government decisions to permit Telework. PublicPersonnel Management. 2017, 46(3), 239-262. DOI: 10.1177/o09102601771240

33. Rocha C, Amador F. Telework: conceptualization and issues for analysis. EBAPE.BR. 2018, 16(1), 152162. DOI: $10.1590 / 1679-395154516$

34. Silva G. Perspetivas sobre o Teletrabalho no contexto da Administração Pública Brasileira: um anteprojeto. Mestrado em Administração Pública da Escola Brasileira de Administração Pública e de Empresas. Fundação Getúlio Vargas. 2014, 1- 88.

35. Felippe G. A Internet e as Novas Tecnologias na relação de Trabalho: telework/ homeoffice e a Jornada de Trabalho. Mestrado em Direito do Trabalho. Pontifícia Universidade Católica de S. Paulo. 2018, 1-121.

36. Jostell D, Hemlin S. After hours teleworking and boundary management: effects on work-family conflict. Work. 2018 (6o), 475-483. DOI: 10.3233/Wor-182748

37. Pezzella M, Bublitz M. A pessoa como sujeito de direitos na sociedade de informação: teletrabalho como forma de inclusão social- um desafio. Pensar. 2014, 19(1), 179-200. 
38. Kwon M, Jeon S. Why permit telework? Exploring the determinants of California City Governments decisions to permit telework. PublicPersonnel Management. 2017, 46(3), 239-262. DOI:

10.1177/0091026017717240

39. Melo E. Teletrabalho, Qualidade de vida no Trabalho e Satisfação Profissional: um estudo exploratório numa amostra de profissionais da área da Tecnologia da Informação. Mestrado Integrado em Psicologia, Faculdade de Psicologia, Universidade de Lisboa. 2011, 1-31.

40. Baggi M. A mobilidade urbana na era digital. Mestrado em Engenharia Ambiental Urbana. Escola Politécnica, Universidade Federal da Bahia. 2012, 1- 154.

41. Garcia M, Guerrero H, Rodríguez E. Condiciones de Seguridad Y Salude enel Trabajo de los Teletrabajadores: RevisíonSistematica. Pensaminento Americano. 2019, 12(23), 94-104. DOI: 10.21803/pensam.v12i22.249

42. Robertson M, Vink P. Examining new ways of office work between the Netherlands and the USA. Work. 2012, 41, 5086- 5090. DOI: 10.3233/WOR-2012-1042-5086

43. Barros A, Silva J. Percepções dos indivíduos sobre as consequências do Teletrabalho na configuração home-office: estudo de caso na Shell Brasil. EBAPE.BR. 2010, 8(1), 72-91.

44. Aderaldo I. Teletrabalho para Estagiários: análise da efetividade do home-office em um programa de estágio. Mestrado de Administração de Empresas. Fundação Edson Queiroz. Universidade de FortalezaUNIFOR. 2016, 1-85.

45. Duxbury L, Halinski M. When more is less: an examination of the relationship between hours in telework and role overload. Work. 2014, 48, 91- 103. DOI: 10. 3233/WOR-141858

46. Bublitz M. Pessoa com Deficiência e Teletrabalho: reflexões à luz do valor social do Trabalho (Inclusão Social e Fraternidade). Mestrado em Fundamentos Constitucionais do Direito Público e Privado. Faculdade de direito, Pontifícia Universidade Católica do Rio Grande do Sul. 2014, 1-26

47. Shepherd- BaniganM, Bell J, Basu A, Booth-Laforce C, Harris J. Workplace stress and working from home influences depressive symptoms among employed women with young children.

InternationalJournalofBehavior Medicine. 2016, 23, 102- 111. DOI:10.1007/s12529-015-9482-2

48. Golden T, Schoenleber A. Toward a deeper understanding of the willingness to seek help: the case of teleworkers. Work. 2014, 48, 83-90. DOI: 10.3233/WOR-131818

49. Miranda P, Miranda L, Pimentel G. O teletrabalho e as possibilidades de violação do direito ao lazer. Revista Brasileira de Estudos do Lazer. 2018, 5(1), 109-125.

Quadro 1- Metodologia da Revisão

\begin{tabular}{|c|c|c|c|c|c|c|c|}
\hline $\begin{array}{l}\text { Motor de } \\
\text { busca }\end{array}$ & $\begin{array}{l}\text { Expressões/ } \\
\text { palavras- } \\
\text { chave }\end{array}$ & Critérios & $\begin{array}{l}N^{\circ} \text { de } \\
\text { documentos } \\
\text { obtidos }\end{array}$ & Pesquisa & $\begin{array}{l}\text { Pesquisa } \\
\text { efetuada } \\
\text { ou não }\end{array}$ & $\begin{array}{l}N^{\circ} \text { do } \\
\text { documento } \\
\text { na } \\
\text { pesquisa e } \\
\text { Codificação } \\
\text { inicial }\end{array}$ & $\begin{array}{l}\text { Codificação } \\
\text { final }\end{array}$ \\
\hline
\end{tabular}




\begin{tabular}{|c|c|c|c|c|c|c|c|}
\hline \multirow{32}{*}{$\begin{array}{l}\text { EBSCO } \\
\text { (CINALH, } \\
\text { Medline, } \\
\text { Database of } \\
\text { Abstracts } \\
\text { and } \\
\text { Reviews, } \\
\text { Central } \\
\text { Register of } \\
\text { Controlled } \\
\text { Trials, } \\
\text { Cochrane } \\
\text { Database of } \\
\text { Systematic } \\
\text { Reviews, } \\
\text { Nursing \& } \\
\text { Allied Health } \\
\text { Collection e } \\
\text { MedicLatina) }\end{array}$} & \multirow[t]{14}{*}{ telework } & \multirow{14}{*}{$\begin{array}{l}\text {-humano } \\
\text {-acesso a } \\
\text { resumo } \\
-2010 \text { a } \\
2020\end{array}$} & \multirow[t]{14}{*}{63} & \multirow[t]{14}{*}{ A } & \multirow[t]{14}{*}{$\operatorname{sim}$} & $\begin{array}{l}14-\mathrm{A} 1 \\
17-\mathrm{A} 2\end{array}$ & $\begin{array}{l}36 \\
38\end{array}$ \\
\hline & & & & & & $21-A 3$ & 47 \\
\hline & & & & & & 26-A4 & 14 \\
\hline & & & & & & 27-A5 & 1 \\
\hline & & & & & & 28-A6 & 45 \\
\hline & & & & & & $29-A 7$ & 2 \\
\hline & & & & & & $30-A 8$ & 3 \\
\hline & & & & & & $31-A 9$ & 4 \\
\hline & & & & & & 32-A10 & 48 \\
\hline & & & & & & & 15 \\
\hline & & & & & & & \\
\hline & & & & & & 39-A12 & 16 \\
\hline & & & & & & $40-\mathrm{A} 13$ & 42 \\
\hline & & & & & & 42-A14 & 17 \\
\hline & teleworking & & 49 & B & & $\begin{array}{l}7-B 1 \\
11-B 2\end{array}$ & $\begin{array}{l}18 \\
41\end{array}$ \\
\hline & & & & & & $12=A 1$ & - \\
\hline & & & & & & 14-B3 & 31 \\
\hline & & & & & & $15-B 4$ & 32 \\
\hline & & & & & & 16-B5 & 19 \\
\hline & & & & & & $17=A 3$ & - \\
\hline & & & & & & $22=A 4$ & - \\
\hline & & & & & & $23=A 6$ & - \\
\hline & & & & & & $24=A 7$ & - \\
\hline & & & & & & $25=A 8$ & - \\
\hline & & & & & & $26=A 9$ & - \\
\hline & & & & & & $28=A 11$ & - \\
\hline & & & & & & 29-B6 & 5 \\
\hline & & & & & & $32=A 12$ & - \\
\hline & & & & & & $34=A 13$ & - \\
\hline & $\begin{array}{l}\text { working at } \\
\text { home }\end{array}$ & & 82 & C & & $\begin{array}{l}25=A 3 \\
32=A 6\end{array}$ & $\begin{array}{l}- \\
-\end{array}$ \\
\hline & & & & & & $42-C 1$ & - \\
\hline & & & & & & $44-C 2$ & - \\
\hline
\end{tabular}




\begin{tabular}{|c|c|c|c|c|}
\hline Remote work & 28 & $D$ & $\begin{array}{l}6=B 1 \\
11=B 3\end{array}$ & - \\
\hline & & & $13=\mathrm{B} 4$ & - \\
\hline & & & $17=\mathrm{A} 3$ & - \\
\hline & & & $22=A 9$ & - \\
\hline & & & $23=B 6$ & - \\
\hline homeworkers & 16 & $E$ & - & - \\
\hline telecomuting & 64 & $\mathrm{~F}$ & $\begin{array}{l}7=\mathrm{B} 1 \\
11=\mathrm{B} 2\end{array}$ & - \\
\hline & & & $14=\mathrm{A} 1$ & - \\
\hline & & & $15=\mathrm{B} 3$ & - \\
\hline & & & $16=\mathrm{B} 4$ & - \\
\hline & & & $19=\mathrm{B} 5$ & - \\
\hline & & & $20=A 3$ & - \\
\hline & & & $28=A 4$ & - \\
\hline & & & $29=A 5$ & - \\
\hline & & & $30=A 6$ & - \\
\hline & & & $31=\mathrm{A} 7$ & - \\
\hline & & & $32=A 8$ & - \\
\hline & & & $33=A 9$ & - \\
\hline & & & $34=A 10$ & - \\
\hline & & & $35=A 11$ & - \\
\hline & & & $36=\mathrm{B} 6$ & - \\
\hline & & & $40=A 12$ & - \\
\hline & & & $42=A 13$ & - \\
\hline & & & $44-\mathrm{F} 1$ & - \\
\hline
\end{tabular}




\begin{tabular}{llll}
\hline RECAAP teletrabalho & $\begin{array}{l}\text {-pesquisa } 156 \\
\text { avançada }\end{array}$ & $\mathrm{R}$
\end{tabular}

R6

R7

R8

R9

Quadro 2- Sistematização das vantagens do teletrabalho

\begin{tabular}{lll} 
Trabalhador & Empregador & Sociedade \\
\hline -Menos conflitos familiares e melhor capacidade para & -Maior facilidade em & -Menos poluição \\
gerir a vida familiar $(2)(6)(7)(8-10)(13)(17)(23)(24)(29)$ & recrutar funcionários & associada ao transito
\end{tabular}


$(31)(33)(35)(36)(37-39)(41)(44)(46)$

-Mais qualidade de vida pessoal e/ ou familiar (1) (2)

$(6-11)(13)(21)(23)(28)(29)(30)(31)(33)(35)(37-39)(41)$ $(43)(44)(46)$

-Maior facilidade em acompanhar os filhos(39)

-Interrupções no trabalho sentidas como

oportunidades, no sentido de poder desfrutar da vida familiar(36)

-Mais tempo livre(7)(11)(29) (44) e/ou mais liberdade/ autonomia para gerir o tempo(11)(43)

-Menos viagens considerando quer o custo(6-10) (12) $(21)(24)(28)(29)(33)(37)(38)(39)(43)(44)(46)$, quer o tempo $(6)(8-13)(15)(19)(21)(24)(25)(28-30)(37)(43)$ (44); podendo utilizar esse tempo para trabalhar(6) (13)(22)(25)(35), aprender, lazer ou resolução de assuntos pessoais(22)(25)(35); salientando-se ainda o menor cansaço (6)(7)(12) (21) (34) (37)(46) ou ansiedade(11)(29)(37) associados às viagens

-Menores custos com a alimentação(13), vestuário, acessórios e manutenção de viatura própria(6)(7)(12) $(21)(34)(37)(46)$, bem como de supervisão de crianças e idosos(6) e saúde(12)

-Mais liberdade para usar roupas mais confortáveis(43)

-Maior liberdade na escolha do local para morar, eventualmente numa zona menos desenvolvida e barata $(6)(11)(21)(34)(35)$

-Menos acidentes de viação(6)

-Menos poluição associada ao transito automóvel(2) $(6)(9-11)(17)(21)(25)(26)(33)(34)(38)(39)(44)$

-Menor exposição à violência urbana(35)(43)

-Maior produtividade (6)(8-13)(21)(25)(29)(33-35)(38) (39)(43)(44)

-Ambiente de trabalho mais agradável e confortável(8)(9)(12)(21)(35)(43)

-Maior autonomia para gerir o trabalho(2)(6)(8)(9)(21) $(23)(25)(30)(31)(36-38)(44)$

-Menos cansaço(39)

-Diminuição de alguns conflitos com os colegas de trabalho(6)(12)(29)

-Maior desenvolvimento pessoal e profissional(29)

-Maior autoestima(21)(29)

-Melhor desempenho(3)(10)(18)

-Menos distrações(6)(11)(21)(22)(25)(39)(43), sobretudo quando se trabalha em open space no posto presencial(43)

-Potenciar a flexibilidade pessoal e laboral(6)(8)(11) $(12)(15)(21)(24)(32-35)(39)(44)(46)$; bem como em relação ao horário e local de trabalho(11)(34) interessados em

teletrabalho(6)(8)(23)(29)

(35)(39), jovens(32)(44)e/

ou muito qualificados,

mesmo que residam

longe $(6)(8)(10)(12)(21-23)$

$(25)(30)(34)(35)(43)(44)$

-Aumentar a

representatividade da

empresa em diversas

zonas do planeta(22)(44)

-Subcontratação de mão de obra mais barata de outros países(8)(12)(25) (34)

-Diminuição do turnover de funcionários $(2)(10-12)$ $(21)(22)(2-31)(34)(38)$

-Maior flexibilização das relações de trabalho(9) (22)

-Menores interrupções no trabalho(25)

-Menos cansaço(39)

-Mais empenho(15)(18)

-Ter funcionários a trabalhar mais horas(13) (15)(35)

-Diminuição do absentismo(6)(7)(10)(11) $(21-23)(25)(26)(29)(30)$ $(33)(34)(39)(43)(44)$

-Conseguir que os funcionários trabalhem mesmo em situação de doença(11)(44)

-Maior produtividade(2)(8) $(11)(15)(21)(22)(25)(29)$ (33)(35)(38)(39)

-Melhor desempenho(3) e eficiência(11)

-Maior lealdade do trabalhador(6)(30)

-Melhor cumprimento de prazos(15)

-Potenciação da aprendizagem entre funcionários(22)

-Maior flexibilidade(13) (22)(30)

-Maior motivação(22)(29) automóvel(2)(6)(9-12)

$(14)(17)(21)(25)(33)$

(34)(38)(39)(44)

-Menor consumo de

combustível(11)(34)

(39)(44)

-Menos transito(7)(8)

(21)(25)(34)

-Menos acidentes rodoviários(21)(34)

-Menores custos na manutenção ou criação de novas infraestruturas rodoviárias(10)(21) (25)

-Mais lugares de estacionamento disponíveis(7)

-Maior

produtividade(2)(8) $(10)(11)(15)(21)(22)$ $(25)(29)(33)(35)(38)$ (39)

-Aumentar o $n^{\circ}$ de postos de trabalho disponíveis(11)(12) (15)(28)(37)(44) ou seja, diminuição do desemprego(43)

-Diminuição das pegadas ecológicas das empresas(6)

-Maior desenvolvimento de zonas mais distantes e/ ou rurais(6)(8)(9) $(11)(21)(25)(33-35)$ (44)- ou seja, melhor ordenamento do território(8)

-Maior inclusão social (trabalhadores com deficiências e/ ou filhos)(7-12)(14)(21) (28)(37)(39), mais idosos e/ ou a viver em zonas mais isoladas(8)

-Maior flexibilização das relações de trabalho(9)(22)

-Diminuição do preço final do produto(12) (35) 
- Trabalhar na altura do dia em que é mais produtivo(9)(11)(29)(39) ou de forma mais homogénea(42); maior controlo no ritmo de trabalho(7)(35)

-Trabalhar mais horas(15)

-Eliminar restrições de fusos horários

-Eliminar restrições associadas a horários de abertura e encerramento

-Possibilitar uma transição mais suave para a reforma(6)

-Diminuição do absentismo para resolver assuntos incompatíveis com o horário laboral(6)(7)(12)(33)(39) (43)(44)

-Diminuição da ansiedade global(6-9)(15)(17)(21)(24) $(26)(34)(42)(47)$

-Possibilitar o acesso ao mercado de trabalho a indivíduos com limitações(3)(6)(7)(9)(11)(14)(21)(2325)(28)(33)(35)(37)(44) (não só, mas sobretudo a nível de mobilidade), bem como idosos, mães em amamentação ou progenitores em geral(7)(21)(33)

-Aumentar o número de postos de trabalho disponíveis(9)(15)(28)(37)

-Menor exposição a microrganismos (colegas e sistemas de ventilação/ aquecimento complexos)

-Menor contato com a chefia(21)

-Maior motivação(8)(9)(22)(29)(34)

-Maior capacidade para se trabalhar, mesmo que doente(22)(39)(44)

-Mais oportunidades de trabalho(6)(9)

-Sensação mais intensa de pertencer à organização(9)

-Potenciar a criatividade(25)

-Possibilidade de trabalhar para vários empregadores(26)

-Maior facilidade em partilhar conhecimentos(43)

-Menor exposição à poluição(13)

-Aumento da autoestima, por sentir que a chefia o considera responsável(29)

-Mais facilidade em praticar desporto(39)

-Mais saúde(30)

-Mais satisfação do trabalhador(3)(12)(18)(21)(24) $(29)(36)(38)$
-Sensação mais intensa de pertencer à

organização

-Melhor ambiente de trabalho(9)

-Melhor imagem da empresa(34)

-Maior controlo do empregador(43)

-Eliminar restrições de fusos horários ou com horários de abertura e encerramento(6); conseguir funcionar 24 horas por dia(24)

-Maior capacidade de resposta perante 0 cliente(6)

-Melhor organização(15)

-Menores despesas energéticas com o local de trabalho a nível de manutenção e/ ou consumíveis (água, café) $(7)(10-13)(22)(29)(30)(33-$ $35)(37)(38)(43)(44)$

-Menor custo imobiliário com a aquisição das instalações (11-13) (24) $(25)(31)(34)(35)(37)(39)$ $(43)(44)(46)$

-Menos despesa a nível de subsídio de alimentação(11)

-Menos custos em relação a parque de estacionamento(11) e/ ou mais lugares de estacionamento disponíveis(7)

-Diminuir o custo do trabalho(2)(12) e maior lucro; ou seja, maior competitividade(7)(8)(12) (25)(35)(43)

-Diminuição do preço final do produto(26)(35)

-Atenua ou soluciona o problema de falta de espaço(29), aumentando a área de trabalho disponivel para os que se mantêm em trabalho presencial
-Maior probabilidade de parte das empresas continuar a funcionar razoavelmente, mesmo com catástrofes (climatéricas, ataques terroristas ou outras situações equivalentes)(21) 
-Melhoria da qualidade do ar interior para os que fazem serviço presencial

-Diminuição da pegada ecológica da empresa(6)

-Maior inclusão social (trabalhadores com deficiências e/ ou filhos) $(7-12)(14)(21)(28)(37)$ (39), mais idosos e/ ou a viver em zonas mais isoladas(8)

-Maior probabilidade de continuar a funcionar razoavelmente, mesmo com catástrofes (climatéricas, ataques terroristas ou outras situações equivalentes) (21)

- Criar mais postos de trabalho(11)(15)(26)(28) (37)(44)

Quadro 3- Sistematização das desvantagens do Teletrabalho

Trabalhador

-Mais conflitos familiares(1)(2)(18)(19)(22)(25)(28)(35) (36)(42)

-Mais ansiedade nos familiares(3)

-Diminuição da privacidade do trabalhador e da sua família(11)

-Menos espaço físico disponível para a vida familiar(6) $(10)(20)(29)$

-Dificuldade em separar a vida profissional da pessoal(1-3)(6-8)(15)(20)(24)(28)(30)(33)(38)(43)(44)

-Menor participação na vida familiar(15)(19)

-Mais interrupções no trabalho/ distrações(1)(10)(12) $(15)(21)(29)(34)(36)(43)$ de familiares e/ ou vizinhos(6)

-Mais interrupções nas tarefas domésticas(1)(22)(36)

-Diminuição do tempo de descanso/ lazer(13)(35)(39) (o funcionário sente-se na obrigação de estar sempre disponível)(8)(35); trabalhar mesmo doente(10)(22) (39)(44)ou durante as férias(44); impossibilidade de faltar(43); ou seja, trabalhar em dias que seriam de descanso(10)

-Trabalhar mais horas(7)(11)(15)(17)(25)(29)(33)(34) (43)

-Maior dificuldade em contabilizar as horas de trabalho(7) ou não ser remunerado por horas extra(29) (44)

-Maior cansaço(29)
Empregador

-Maior dificuldade das chefias para monitorizar o desempenho(6)(9)(10)(17)(20) $(24)(28-30)(32-35)(38)$ controlar eventuais atitudes negativas(32)(38)

-Necessidade de reestruturar o modelo de gestão/ supervisão/ liderança(8)(29)(44)

-Risco de recrutamento de funcionários desadequados ao TT(12)(25)(44); aumento dos custos de recrutamento se se usar uma agência(44)

-Menor produtividade(10)(12) (38) ou desempenho(18)

-Descontentamento dos funcionários por trabalharem mais horas(15)(17); por gerirem mais tarefas ou associado a questões culturais que depreciam o TT(8)

-Maior dificuldade em contabilizar as horas trabalho e remuneração associada(22)

-Maior perceção da parte do trabalhador de não estar integrado na empresa(30)(31) (33)
Sociedade

-Menor produtividade(38)

-Menor solidariedade profissional

-Menor capacidade de interação social(21)

-Maior precarização das relações de trabalho(12)(22)

-Acesso facilitado a mão de obra mais barata e respetiva exploração(11) (25)

-Mais patologia músculoesquelética(44) -Infoexclusão(13) (25)(37) 
-Gerir mais tarefas e/ ou ter essa perceção(17)

-Maior probabilidade de violação dos direitos de trabalho(35), menor legislação protetora(34)(44)

-Ter de responder a objetivos/ metas mais exigentes da parte do empregador(13)(29)(35), maior esforço para provar o seu valor(43)

-Menor produtividade(1)(38) ou desempenho(18)

-Mais ansiedade do trabalhador(1)(24)(47)

-Diminuição da qualidade de vida(24)

-Maior isolamento social e profissional(2)(3)(5-13)(17) $(19-21)(23)(25)(29-31)(33)(35)(39)(42-44)$ bem como político(33) (ou seja, a nível sindicalista(11)(28)(34))

-Maior afastamento da cultura de trabalho da empresa(5)(8)(10), das chefias(44) e do espírito de equipa(29); maior perceção de não estar integrado na empresa(10)(13)(31); maior falta de apoio social(17); diminuição do trabalho de grupo(8)

-Exigir mais autodisciplina(7)(11); diminuição do trabalho de grupo(8)

-Maior dificuldade de progressão na carreira(2)(5)(811)(17)(20)(22)(23)(25)(28)(29)(31)(34)(43); mais facilmente passar mais despercebido às chefias, menor visibilidade laboral(5)(23)(31)(43)(44)

-Diminuição da aprendizagem(5)(6)(8)(10)(25)(35)

-Menor autonomia(17)(33)

-Ausência de apoio sénior presencial(17)

-Menos apoio para resolver problemas técnicos/ informáticos(5)(12)(25)(31)(44)

-Ter de lidar com o preconceito de se trabalhar menos do que presencialmente(5) ou que o TT não é trabalho válido ou sério(13)(26)(29)

-Perda de subsídio de viagem e/ ou alimentação(6)(8)

-Maior despesa energética(6)(10)(22)(34)(43)(44)

(30)e/ ou informáticas/ mobiliárias do domicílio(6)(22)

$(30)(34)(43)(44)$

-Menor salário(13)

-Maior sedentarismo(15)

-Maior dificuldade em se readaptar novamente ao trabalho presencial(6)

-Agravamento de algumas dependências(9)(11)(12) (comida, álcool e outras drogas, trabalho)(11)(21)

-Maior controlo de desempenho pelas chefias devido à tecnologia(22)(43)

-Aumento do desinteresse pelo trabalho(8)

-Menor motivação(12)

-Menor lealdade à empresa(34)
-Menor lealdade para a instituição(21)

-Maior afastamento da cultura de trabalho da empresa(5)(6) (21)(25)

-Conflito entre os selecionados e não selecionados para o TT(9)(21)(32)

-Diminuição da aprendizagem do trabalhador(5), sobretudo com colegas(21); diminuição do trabalho de equipa(29)

-Maior dificuldade para resolver problemas informáticos(6)

-Diminuição do controlo das condições de segurança do novo local de trabalho(6)(8) e/ ou ambiente de trabalho menos seguro(17)

-Investimentos tecnológicos elevados(6)(8)(9)(12)(25)(29) (30)(35)

-A formação dada para o funcionário se tornar teletrabalhador pode ficar dispendiosa(6) e/ ou a empresa sentir as consequências pela ausência de formação(8)

-Maior dificuldade a gerir dados que necessitem de sigilo(8)(12)(24)(29)(30)(34)

(35) uso de computadores pessoais menos seguros nesse contexto(30)

-Maior dependência tecnológica(24)

-Eventual necessidade de readaptação/ formação(10) para o funcionário voltar ao trabalho presencial

-Menos criatividade com turnos mais prolongados(43)

-Menor interação criativa entre colegas(29) 
-Maior responsabilidade nas condições de segurança laborais(10) e/ ou maior exposição a estes riscos e eventual surgimento de lesões músculoesqueléticas(35);ambiente de trabalho menos seguro(17);mais problemas ergonómicos(11); área de trabalho menor(29)

-Dificuldade em gerir o tempo(10)

-Maior dependência tecnológica(24)

-Maior exigência em termos de automotivação, disciplina e organização(43)

-Caso haja necessidade de efetuar despedimentos, os teletrabalhadores poderão ser os primeiros, uma vez que têm laços sociais mais ténues(11)

-Maior probabilidade de adiar tarefas por não ter supervisão presencial no momento(12)

-Menos criatividade com turnos mais prolongados

-Aumento dos gastos (se fizer mais viagens em lazer e/ ou mais compras)

-Ter de arrumar a casa para receber algum representante do empregador

-Menor acesso às novidades da empresa

-Maior irregularidade dos turnos(43)

-Infoexclusão(13)(34)(37)

-Refeições mais irregulares(6)(15)

-Menor autoestima(31)

-Menor satisfação global(1)(38)

-Maior insatisfação com o empregador(8)

\section{(1)Mónica Santos}

Licenciada em Medicina; Especialista em Medicina Geral e Familiar; Mestre em Ciências do Desporto; Especialista em Medicina do Trabalho e Doutoranda em Segurança e Saúde Ocupacionais, na Faculdade de Engenharia da Universidade do Porto. Presentemente a exercer nas empresas Medicisforma, Securilabor e Medimarco; Diretora Clínica da empresa Quercia; Diretora da Revista Portuguesa de Saúde Ocupacional online. Endereços para correspondência: Rua Agostinho Fernando Oliveira Guedes, 42, 4420-009 Gondomar. E-mail: s_monica_santos@hotmail.com

\section{(2)Armando Almeida}

Enfermeiro Especialista em Enfermagem Comunitária, com Competência Acrescida em Enfermagem do Trabalho. Doutorado em Enfermagem; Mestre em Enfermagem Avançada; Pós-graduado em Supervisão Clínica e em Sistemas de Informação em Enfermagem; Professor Auxiliar Convidado na Universidade Católica Portuguesa, Instituto da Ciências da Saúde - Escola de Enfermagem (Porto) onde Coordena a Pós-Graduação em Enfermagem do Trabalho; Diretor Adjunto da Revista Portuguesa de Saúde Ocupacional online. 4420-009 Gondomar. E-mail: aalmeida@porto.ucp.pt 


\section{(3)Catarina Lopes}

Licenciada em Enfermagem, desde 2010, pela Escola Superior de Saúde Vale do Ave. A exercer funções na área da Saúde Ocupacional desde 2011 como Enfermeira do trabalho autorizada pela Direção Geral de Saúde, tendo sido a responsável pela gestão do departamento de Saúde Ocupacional de uma empresa prestadora de serviços externos durante 7 anos. Atualmente acumula funções como Enfermeira de Saúde Ocupacional e exerce como Enfermeira Generalista na SNS24. Encontra-se a frequentar o curso Técnico Superior de Segurança do Trabalho.4715-028. Braga. E-mail: catarinafflopes@gmail.com

\section{(4)Tiago Oliveira}

Licenciado em Enfermagem pela Universidade Católica Portuguesa. Frequenta o curso de Técnico Superior de Segurança no Trabalho. Atualmente exerce a tempo inteiro como Enfermeiro do Trabalho. No âmbito desportivo desenvolveu competências no exercício de funções de Coordenador Comercial na empresa Academia Fitness Center, assim como de Enfermeiro pelo clube de futebol União Desportiva Valonguense. 4435-718 Baguim do Monte. E-mail: tiago_sc16@hotmail.com 